\title{
Development of High-flow and Crack-reduction Method for CFT Internal Mass Concrete
}

\author{
Dong-oun $\mathrm{Lee}^{1}$ and Gi-hwan $\mathrm{Oh}^{2 *}$ \\ ${ }^{1}$ Professor, Department of Architectural \& Civil Engineering, DongSeo University, \\ Busanjin-gu, Busan, Korea \\ ${ }^{2}$ Professor, Department of mechatronis engineering, DongSeo University, Busanjin- \\ gu, Busan, Korea \\ ${ }^{1}$ ldu21@dongseo.ac.kr, ${ }^{2}$ johnoh@dongseo.ac.kr
}

\begin{abstract}
Recently, downtown buildings have tended to be super-high in connection with the rise in land prices and efficient use of buildings. In accordance with this trend, high-strength concrete is adopted for the structure of the building in relation to the improvement of crosssection efficiency, high-concrete concrete is reviewed in connection with good workability, and high-durability concrete for long-life buildings is used. In the case of large columns of, in addition to the safety of the structure, a very thick CFT inner mass concrete is adopted. Therefore, this study aims to solve the problem by using the case of CFT internal mass concrete as a target structure, as well as low heat mixing and separating mat concrete into multiple layers, adjusting the super-retardant amount in the lower layer. Through the pilot test results, it was confirmed that the internal temperature of the concrete was lowered and the fluidity increased through the decrease of the hydration heat at $36.5 \% \mathrm{~W} / \mathrm{B}$. Therefore, it is intended to secure the integrity between the upper and lower pouring concrete.
\end{abstract}

Keywords: CFT, Mass concrete, Crack-reduction, High-flow, Large column

\section{Introduction}

Recently, buildings in urban areas tend to be super-high-rise in connection with the rise in land prices and the efficient use of buildings [1][2]. According to this trend, high-strength concrete is adopted for structures related to the improvement of cross-section efficiency, high-durable concrete is reviewed for high-density concrete in relation to good construction and high-durable concrete is used for buildings with long lifespan, in addition to this, very thick internal mass concrete is adopted in connection with the safety of the structure [3][4].

However, it is important to solve the problem of cracks caused by hydration heat, especially when the time difference occurs due to the inability to lay large amounts of concrete simultaneously depending on the conditions of the site, not only the unity of the concrete but also the occurrence of stress due to the time difference. In severe cases, massive cracks occur within 24 hours, leading to serious damage to water density and durability [5].

Theoretical consideration collects and investigates literature on the hydration reaction of cement, overview of mass concrete inside CFT, characteristics of super-delayed concrete and

Article history:

Received (May 25, 2020), Review Result (June 29, 2020), Accepted (August 5, 2020) 
the method of condensation time differential, and discusses the possibility of utilization of condensation time differential method by super-delayed agent. Therefore, in order to solve problems with structures using CFT and mass concrete, this study aims to secure unity between top and top-floor concrete by separating insulation by low-heating and doublebubble sheets and placing confluents in the lower layer after separating the matte concrete into several layers [6][7].

\section{Subject}

\subsection{Overview of CFT internal mass concrete}

\subsubsection{Definition and concept of CFT Internal mass concrete}

Recently, columns, beams, and bearing walls are also mass concrete inside the CFT, resulting in harmful cracks in structures. In general, the absence dimensions of concrete structures, which should be treated with mass concrete inside the CFT are difficult to determine uniformly, depending on the structure type, materials used and construction conditions but are generally considered to be mass concrete over $0.8 \mathrm{~m}$ if they are members of a wide flat structure or column shape [2][4]. However, in cases where sub-assembled concrete is used, such as prestressed concrete structures, even thinner members may be subject to the application under the constraints [3].

\subsubsection{The mechanism and characteristics of temperature crack generation in mass concrete inside CFT}

The cause of crack generation of mass concrete inside CFT consists of crack mechanism by internal and external binding stress. Cracks caused by internal binding stress are high in concrete due to the hydration heat of cement and low in surface due to the influence of ambient air temperature, especially the tensile stress acts on the side facing the outside air, resulting in cracks [5][6].

Cracks caused by external binding stress are the same as thick wall members, which are constructed by connecting with steel bars to concrete that has been laid out first and cracks occur during the shrinkage process when the temperature is equal to the ambient temperature after reaching the highest temperature if there is an external gradient [1].

\subsection{Retarder and super retarding agent summary}

Cement mortar and concrete gradually reduce their liquidity after mixing, and hours later, they reach the condensation process corresponding to the time of strength development. The mixture used to prolong the time required for condensation is defined as condensation retardant, generally classified as delay agent and super delay agent, and the mixture representing short-term delay within hours is called retardant and the condensation time can be adjusted from hours to days depending on the arbitrary setting of the additive, and the mixture is called super retardant, which does not adversely affect the property after curing of concrete [8]. This method is to solve the problem of cracking by heat of hydration if the large column mat members are mass concrete. The method is to develop a low and good-quality super retardant by mixing white sugar solution, PEO multiplier and AE agent in a certain proportion [9] and to remove the upper and lower sections of super-delay concrete 
manufactured by mixing a certain amount of super-delay agent and at the same time by placing all concrete on the upper part [Table 1].

Table 1. Experiment plan

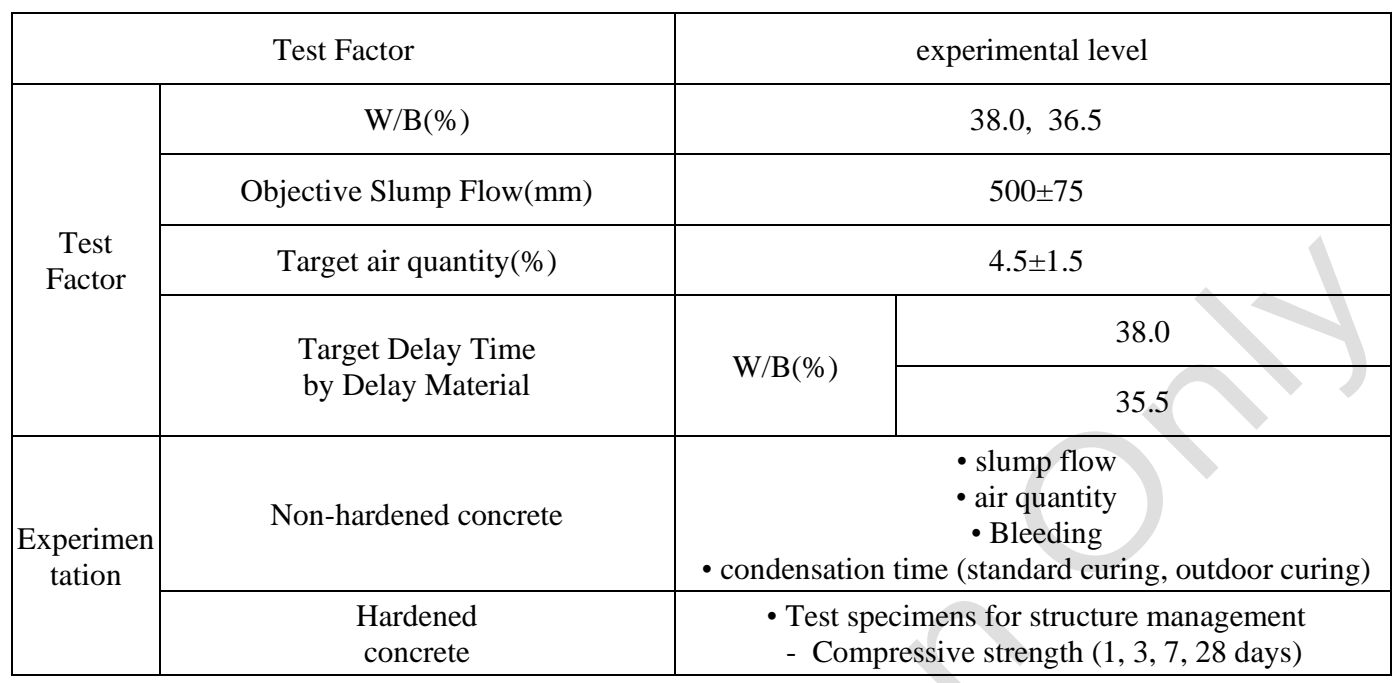

\subsection{Experimental method}

Combinations and aggregates selected for this experiment were generally used by Daeyang Remicon Co., Ltd., located in Yangsan, Gyeongsangnam-do, and the physical and chemical properties of super-delayed materials are as shown in [Table 2].

Table 2. Physical and chemical properties of delayed materials

\begin{tabular}{|c|c|c|c|c|c|c|}
\hline $\begin{array}{c}\text { hybridized } \\
\text { material type }\end{array}$ & principal component & $\begin{array}{c}\text { Colors and } \\
\text { forms }\end{array}$ & $\begin{array}{c}\text { Density } \\
(\mathrm{g} / \mathrm{cm} 3)\end{array}$ & $\mathrm{pH}$ & $\begin{array}{c}\text { a chemical } \\
\text { formula }\end{array}$ & $\begin{array}{c}\text { operative } \\
\text { element }\end{array}$ \\
\hline $\begin{array}{c}\text { delayed } \\
\text { materials }\end{array}$ & $\begin{array}{c}\text { Sucrose, Poly ethyene } \\
\text { oxide, }\end{array}$ & White, Liquid & 1.2 & 7 & $\mathrm{C} 12 \mathrm{H} 22 \mathrm{O} 11$ & $-\mathrm{OH}$ \\
\hline
\end{tabular}

\section{Test results}

\subsection{Slump flow, air and bleeding amount}

[Table 3] shows the experimental results of the concrete that is not hardened during the preliminary test, and [Figure 1] and [Figure 2] shows the amount of slump flow and air over W/B and latency. Normal concrete without a mixture of delayed materials was found to meet the target slump flow of $500 \pm 75 \mathrm{~mm}$ and the target air volume of $4.5 \pm 1.5$ per cent. First of all, liquidity tends to increase somewhat with longer target delay times, which is attributed to an increase in the amount of delayed materials mixed, increasing the amount of liquid used in the actual mix, and requiring a correction of the arrangement to reduce the unit quantity or water rehydrating material when applied to the actual structure in the future. In addition, the volume of air tends to decrease slightly with the longer the target delay time, but there is no significant difference, but it is also necessary to consider the addition of AE materials in the actual shipment. However, the bleed test result did not measure the bleed in any case. 
Table 3. Results of the experiment on non-hardened concrete

\begin{tabular}{|c|c|c|c|c|}
\hline $\begin{array}{c}\text { W/B } \\
(\%)\end{array}$ & Target Latency & $\begin{array}{c}\text { mixed rate } \\
(\%)\end{array}$ & $\begin{array}{c}\text { slump flow } \\
(\mathrm{mm})\end{array}$ & $\begin{array}{c}\text { air quantity } \\
(\%)\end{array}$ \\
\hline \multirow{3}{*}{38.0} & 0 & 0 & 575 & 4.2 \\
\cline { 2 - 5 } & 8 & 0.15 & 615 & 4 \\
\cline { 2 - 5 } & 24 & 0.31 & 625 & 3.5 \\
\hline \multirow{3}{*}{36.5} & 0 & 0 & 563 & 5.2 \\
\cline { 2 - 5 } & 6 & 0.12 & 596 & 5 \\
\hline
\end{tabular}

\subsection{Condensation time}

[Figure 1] and [Figure 2] represent the penetration resistance according to the elapsed time by W/B and latency. First, at the standard curing W/B 38.0\%, the target delay of 8 hours was delayed by approximately 11 hours, the target delay of 24 hours was delayed by approximately 33 hours, and the target delay of 6 hours at the standard curing W/B of 36.5 percent. The target delay time of 8 hours was delayed by approximately 5 hours in the outpatient W/B 38.0\%, the target delay of 24 hours was delayed by approximately 23 hours, and the target delay of 6 hours in the outpatient W/B 36.5 percent was delayed by approximately 4 hours.

Compared to standard and outdoor curing, the delay time was promoted by about 2 to 10 hours, and the delay time increase increased as the rate of mixture of delayed materials increased. Therefore, since the temperature will be higher than the outside due to the high hydration heat of concrete during the actual experiment, the mixing ratio is required to increase the mixture by setting the curing temperature high when calculating the mixing rate of delayed materials [10][11]. This condensation delay is attributed to the prolonged delay in hydration reaction by temporarily blocking contact with water by adsorbing - $\mathrm{OH}$, the action element of the chunks of the developed delayed material, to the surface of the cement particles or to the hydration reactant in the polar phase [12].

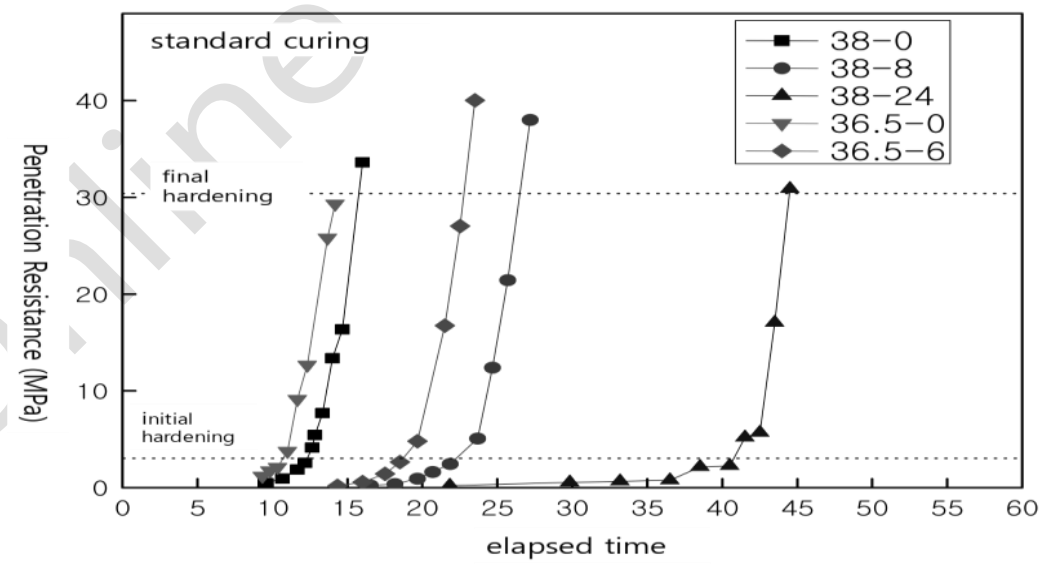

Figure 1. Penetration resistance values according to elapsed time by W/B and latency (standard curing) 


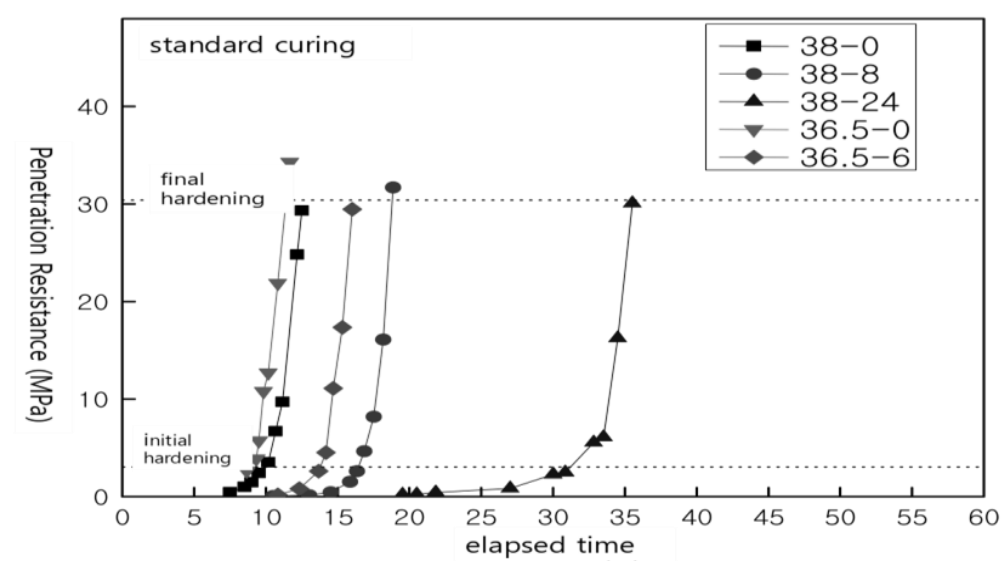

Figure 2. Penetration resistance values according to elapsed time by W/B and latency (outdoor curing)

\subsection{Compressive strength characteristics}

[Table 4] and [Figure 3] represent compression strength over elapsed time by W/B and latency. Overall, ultra-delayed concrete with super-delayed materials compared to general concrete without super-delay materials at each W/B showed a small compressive strength due to delay action in the case of initial age, but as the age passed, the width of strength enhancement was greater, indicating a value equal to that of ordinary concrete from the 28th. In particular, 38-24 showed a sharp increase in intensity as the age passed despite the fact that it was impossible to measure the intensity of one day after 35 hours of closure, and the highest value was $48.9 \mathrm{MPa}$ at the age of 28th. It is analyzed that if the hydration reaction progresses slowly due to the initial condensation retardation of sign language, this results in a dense hydration product, which results in the internal tissue becoming more dense.

Table 4. Compressive strength characteristics

\begin{tabular}{|c|c|c|c|c|c|c|}
\hline \multirow{2}{*}{$\begin{array}{c}\text { W/B } \\
(\%)\end{array}$} & \multirow{2}{*}{$\begin{array}{c}\text { Target } \\
\text { Latency }\end{array}$} & \multirow{2}{*}{$\begin{array}{c}\text { mixed rate } \\
(\%)\end{array}$} & \multicolumn{4}{|c|}{ Compressive strength (MPa) } \\
\cline { 4 - 7 } & & & Day 1 & Day 3 & Day 7 & Day 28 \\
\hline \multirow{3}{*}{38.0} & 0 & 0 & 11.5 & 24.9 & 35.0 & 47.3 \\
\cline { 2 - 7 } & 8 & 0.15 & 7.56 & 21.4 & 33.7 & 48.0 \\
\hline \multirow{3}{*}{36.5} & 24 & 0.31 & 0 & 18.0 & 31.9 & 48.9 \\
\cline { 2 - 7 } & 0 & 0 & 12.2 & 27.0 & 36.0 & 48.0 \\
\hline
\end{tabular}




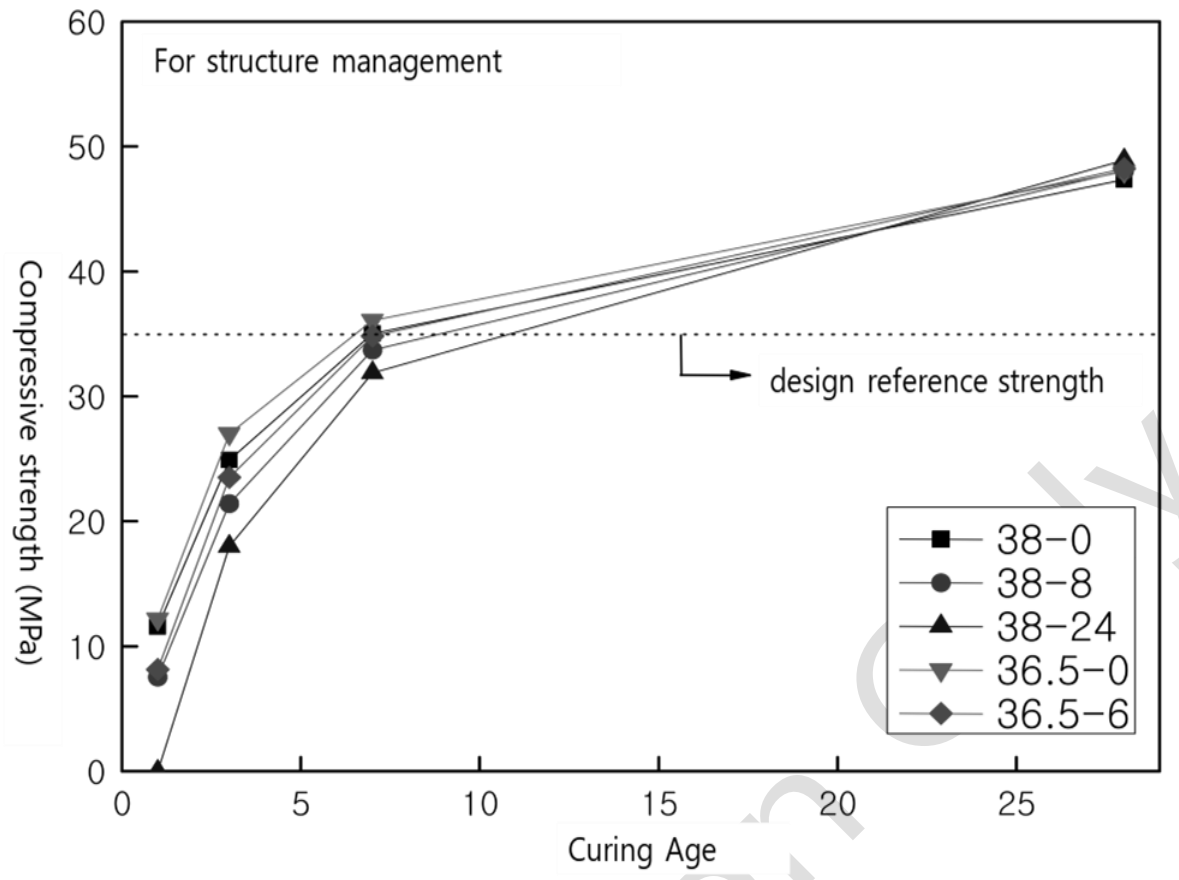

Figure 3. Compressive strength according to elapsed time by W/B and latency

\section{Conclusion}

Through this study, it was possible to confirm a method of improving the quality performance of concrete, a construction material. The quality of construction materials changes greatly depending on the combination of various materials and environmental changes. There are many differences between the result value and the result value applied to the construction site. This is construction, process, regional material characteristics, etc. Since it occurs due to various variables, a method to minimize quality fluctuations should also be considered. The method of adjusting the hydration heat of the mass concrete of the foundation mat of the building was conducted with an experiment using super-delay agent, and the results are as follows. The method of condensation time difference of mass concrete in a super-delay agent is to fundamentally prevent cracks caused by lack of tensile stress caused by the concrete installed first reacting to hydration during the construction of upper and lower section for working-level mat concrete. In addition, slow down the temperature of hydration and heat. The results of the pilot test were able to secure the mix design data applicable to the practice, and the review of the quality changes caused by the use of super-delay agents showed that although there was a slight increase in liquidity and a decrease in air volume, it could be managed by fine-tuning the arrangement at the time of shipment of the workinglevel ready-mixed concrete. In addition, bleeding did not occur in any case, and condensation time tended to be delayed similarly to the target while the temperature was highly dependent upon the increase in the addition of super retardant, and in the case of compressive strength, the initial age was shown to be relatively low as the addition of super retardant increased, but similar or greater value was shown at the age of $28^{\text {th }}$. In the future, the research direction is to proceed with the influence of temperature and humidity, which changes according to various construction conditions and external environment at the construction site. Through this, it will 
be possible to verify the effectiveness of the actual building by confirming the change in the quality of the material.

\section{Acknowledgements}

This paper was funded by the government (Ministry of Education, Science and Technology) in 2017 with support from the Korea Research Foundation (NRF-2017R1D1A3B05030876)

\section{References}

[1] Jian-ping Chou, Li-chao Chen, YingJun Zhang, and Li-hu Pan, "OPC unified architecture for industrial demand response," International Journal of Security and Its Applications, vol.6, no.2, April, pp.275-280, (2012)

[2] Yun sang Byun and Jin Kwak, "Security management architecture for secure smartwork center ," International Journal of Security and Its Applications, vol.7, no.5, September, pp.315-320, (2013) DOI: 10.14257/ijsia.2013.7.5.29.

[3] Huang Feijiang, Li Xiaoyong, Sun Liping, Sheng wang, Zhang Wenxi, and Liu Guangcan, "Design of layered aerospace time synchronization architecture and time synchronization links budget comparison," International Journal of Future Generation Communication and Networking, vol.6, no.6, December, pp.47-60, (2013) DOI: 10.14257/ijfgen.2013.6.6.06.

[4] Patrik Huss, Niklas Wigertz, Jingcheng Zhang, Allan Huynh, Qinzhong Ye, and Shaofang Gong, "Flexible architecture for internet of things utilizing an local manager," International Journal of Future Generation Communication and Networking, vol.7, no.1, February, pp.235-248, (2014) DOI: 10.14257/ijfgen.2014.7.1.24.

[5] Weiqing Qu, Yuedou Qi, Qi Zhang, and Chunliang Zhou, "Improved RFID middleware architecture and optimal algorithm based on internet of things," International Journal of Future Generation Communication and Networking, vol.9, no.11, November, pp.263-274, (2016) DOI: 10.14257/ijfgcn.2016.9.11.24.

[6] Liu Jinsen, Li Lijuan, Lu Sibin, and Zhang Yan, "Life-cycle management research in power grid construction project," International Journal of Grid and Distributed Computing, vol.9, no.9, September, pp.93-102, (2016) DOI: 10.14257/ijgdc.2016.9.9.09.

[7] Bea Y.H., "Korea institute of construction \& transportation technology evaluation and planning," "development performance measurement for construction technology research, pp.2-32, 1512, (2009)

[8] Yulei Zhang and Caifen Wang, "Comment on new construction of efficient certificateless aggregate signatures," International Journal of Security and Its Applications, vol.9, no.1, January, pp.147-154, (2015) DOI: 10.14257/ijsia.2015.9.1.16.

[9] Zhou Jun, Zhang Hongwei, and Liu Yingjia, "Clean development mechanism and its risk management policy in urban infrastructure construction," International Journal of Security and Its Applications, vol.9, no.7, July, pp.37-48, (2015) DOI: 10.14257/ijsia.2015.9.7.03.

[10] Abdelmadjid Guerouad, Mohamed Bourahla, Mustapha Benghanem, and Abdelhaq Amar Bensaber, "Exponential sliding mode control of electrical vehicle with load observer for disturbance compensation," International Journal of Grid and Distributed Computing, vol.12, no.1, June, pp.43-52, (2019) DOI: 10.14257/ijgdc.2019.12.1.04.

[11] Ajeet Singh and Anurag Jain, "Financial fraud detection using bio-inspired key optimization and machine learning technique," International Journal of Security and Its Applications, vol.13, no.4, December, pp.75-90, (2019) DOI: 10.33832/ijsia.2019.13.4.08.

[12] N. Thirupathi Rao, Debnath Bhattacharyya, and Tai-Hoon Kim, "Security issues and attacks in wireless sensor networks: some case studies," International Journal of Security and Its Applications, vol.12, no.5, September, pp.1-10, (2018) DOI: 10.14257/ijsia.2018.12.5.01. 
This page is empty by intention. 